\title{
Increasing uterine response to vaginal distension during late pregnancy in sheep
}

\author{
M. D. Mitchell, A. P. F. Flint and A. C. Turnbull \\ Nuffield Department of Obstetrics and Gynaecology, John Radcliffe Hospital, \\ Headington, Oxford $O X 39 D U, U . K$.
}

\begin{abstract}
Summary. Intrauterine pressure changes were monitored in 5 pregnant ewes and uterine venous prostaglandin (PG) F concentrations were determined after distension of the vagina. Uterine contractility and utero-ovarian PGF concentrations were elevated by vaginal distension and the magnitude of both effects increased as parturition approached.
\end{abstract}

\section{Introduction}

The 'Ferguson Reflex', enhanced uterine contractility after stretching of the cervix and vagina of puerperal rabbits (Ferguson, 1941), occurs in sheep. Oxytocin is the humoral component of the reflex and its circulating level rises within $1 \mathrm{~min}$ of vaginal distension in cyclic and lactating sheep (Roberts \& Share, 1968; Debackere, Peeters \& Tuyttens, 1961). Vaginal distension in pregnant sheep results in elevated uterine venous prostaglandin (PG) F levels (Flint, Anderson, Patten \& Turnbull, 1974) and a surge of oxytocin during vaginal distension precedes this elevation (Flint, Forsling, Mitchell \& Turnbull, 1975). To determine whether the Ferguson Reflex is enhanced before the onset of parturition we performed serial vaginal distensions on sheep in late pregnancy and monitored intra-amniotic pressure changes, while taking uterine venous blood samples for PGF estimations.

\section{Materials and Methods}

Five ewes of the Dorset, Suffolk and Border Leicester breeds were used and gestational ages at operation for insertion of utero-ovarian venous and amniotic catheters by the methods described by Flint et al. (1974) ranged from 123 to 132 days. In Ewe 3 a catheter was inserted into the fetal inferior vena cava via a tarsal vein. Ewe 2 gave birth spontaneously on Day 141 of gestation; the first fetus died during an obstructed birth, but the second fetus was born alive. All four other animals produced live lambs. Ewe 3 gave birth $44 \mathrm{~h}$ after the start of intrafetal infusion of dexamethasone $(1 \mathrm{mg} / 24 \mathrm{~h}$ ), and Ewes 1, 4 and 5 gave birth 33, 44 and $60 \mathrm{~h}$, respectively, after intrafetal injection of dexamethasone ( $25 \mathrm{mg}$ i.m.). The technique of dexamethasone induction of parturition (Liggins, 1968; Mati, Horrobin \& Bramley, 1973) results in changes of progesterone, oestrogen and PGF concentrations comparable to those preceding the natural onset of parturition (Thorburn, Nicol, Bassett, Shutt \& Cox, 1972; Liggins, Fairclough, Grieves, Kendall \& Knox, 1973; Flint et al., 1974). Vaginal distension was effected manually while the animals remained in metabolism cages. Blood samples were collected into ice-cold heparinized tubes and centrifuged within $1 \mathrm{~h}$; plasma was stored at $-20^{\circ} \mathrm{C}$. Progesterone, total unconjugated oestrogens and PGF were measured by radioimmunoassays as described by Flint et al. (1974) and Mitchell et al. (1975).

\section{Results}

Sharma \& Fitzpatrick (1974) showed that frequently repeated administration of oxytocin resulted in attenuated response of the uterus in terms of PGF output, and this effect is also seen after repeated 
vaginal distension in late pregnancy (Text-figs $1 \mathrm{a}$ and $1 \mathrm{~b}$ ). For this reason vaginal distension was not repeated more than three times in any animal. As shown in Text-figs 1(c) and 1(d) the length of time for which the vagina was distended did not appear to alter substantially the responses measured.

The abdominal straining which occurs during vaginal distension (Text-figs 1 and 2) was a consistent finding and is characteristic of the second stage of parturition, as noted in the goat (Peeters, De Vos \& Houvenaghel, 1971), but was unaffected by the endocrine status of the ewe. The $20 \mathrm{~min}$ after vaginal distension were considered as the experimental period and uterine activity was measured in terms of Montevideo units as defined by Caldeyro-Barcia et al. (1957). The increased uterine contractility following vaginal distension becomes marked close to parturition (Text-fig. 2) and may lead to rhythmic contractions (Text-fig. 2c). In Ewe 5 (Text-fig. 2) there was a 1·6-, 2-5- and 3.7-fold stimulation of uterine activity at 50,31 and $15 \mathrm{~h}$, respectively, before birth. In Ewe 3 there was no stimulation and a 1.5-fold stimulation of uterine activity at 41 and $14 \mathrm{~h}$, respectively, before parturition. Ewe 4 showed a 1.3-fold stimulation at $37 \mathrm{~h}$ before and a $3 \cdot 3$-fold stimulation at $20 \mathrm{~h}$ before birth (pressure traces not shown). Increased contractility occurred for a variable time, but appeared to continue longer close to parturition (Text-fig. 2), sometimes not returning to prestimulation levels. Another feature of the intrauterine pressure changes was the variable uterine hypertonus occurring for approximately $5 \mathrm{~min}$ immediately after vaginal distension (see Text-fig. 1c especially).

The increases in response to vaginal distension were concurrent with falling levels of progesterone in maternal plasma (Table 1). No effects could be ascribed to rising oestrogen levels; as shown in Table 1 changes in uterine sensitivity preceded any large increases in oestrogens.

Table 1. Experimental details of sheep

\begin{tabular}{|c|c|c|c|c|}
\hline \multirow[b]{2}{*}{ Ewe } & \multirow[b]{2}{*}{ Time of birth } & \multirow[b]{2}{*}{$\begin{array}{c}\text { Time of } \\
\text { exp. before } \\
\text { birth }\end{array}$} & \multicolumn{2}{|c|}{ Utero-ovarian venous conc. } \\
\hline & & & $\begin{array}{l}\text { Progesterone } \\
\quad(\mathrm{ng} / \mathrm{ml})\end{array}$ & $\begin{array}{c}\text { Total } \\
\text { unconjugated } \\
\text { oestrogens } \\
(\mathrm{pg} / \mathrm{ml})\end{array}$ \\
\hline \multirow[t]{2}{*}{1} & $33 \mathrm{~h}$ after & $8 \mathrm{~h}$ & 48 & 120 \\
\hline & dexamethasone & $3 \cdot 5 \mathrm{~h}$ & 32 & 340 \\
\hline 2 & $\begin{array}{l}141 \text { days post } \\
\text { coitum }\end{array}$ & 7 days & $44 \cdot 5$ & 102 \\
\hline \multirow[t]{2}{*}{3} & $44 \mathrm{~h}$ after & $41 \mathrm{~h}$ & 55 & 54 \\
\hline & dexamethasone & $14 \mathrm{~h}$ & 26 & 100 \\
\hline \multirow[t]{2}{*}{4} & $44 \mathrm{~h}$ after & $37 \mathrm{~h}$ & 58 & 100 \\
\hline & dexamethasone & $20 \mathrm{~h}$ & $23 \cdot 3$ & 176 \\
\hline \multirow[t]{3}{*}{5} & $60 \mathrm{~h}$ after & $50 \mathrm{~h}$ & $18 \cdot 5$ & 60 \\
\hline & dexamethasone & $31 \mathrm{~h}$ & $3 \cdot 6$ & 180 \\
\hline & & $15 \mathrm{~h}$ & $0 \cdot 7$ & 112 \\
\hline
\end{tabular}

The time course of the rise in PGF concentrations in response to vaginal distension was similar to that found by Flint et al. (1975); peak levels 3-5 min from the beginning of vaginal distension fell to basal values within $30 \mathrm{~min}$. Minimal changes in PGF concentrations were found 7 days before parturition (data not shown) or shortly after the start of dexamethasone treatment (Text-fig. 2d) and in Ewes 3 and 4 at 41 and $37 \mathrm{~h}$, respectively, before birth (data not shown). As progesterone concentrations fell (Table 1), markedly elevated PGF concentrations were obtained in response to vaginal distension (Text-fig. 2d), and in Ewes 3 and 4 at 14 and $20 \mathrm{~h}$, respectively, before birth there were 4- and 2-fold elevations of PGF concentrations in utero-ovarian venous plasma (data not shown).

\section{Discussion}

This work demonstrates an increasing uterine response to vaginal distension in terms of both contractility and plasma PGF concentrations. Of interest also are the two factors which do not change 


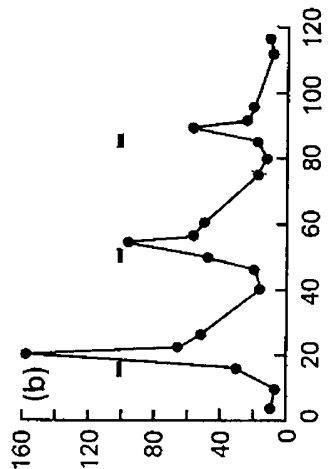

$(\mid \omega / 6 u) \sqsupset 9 d$
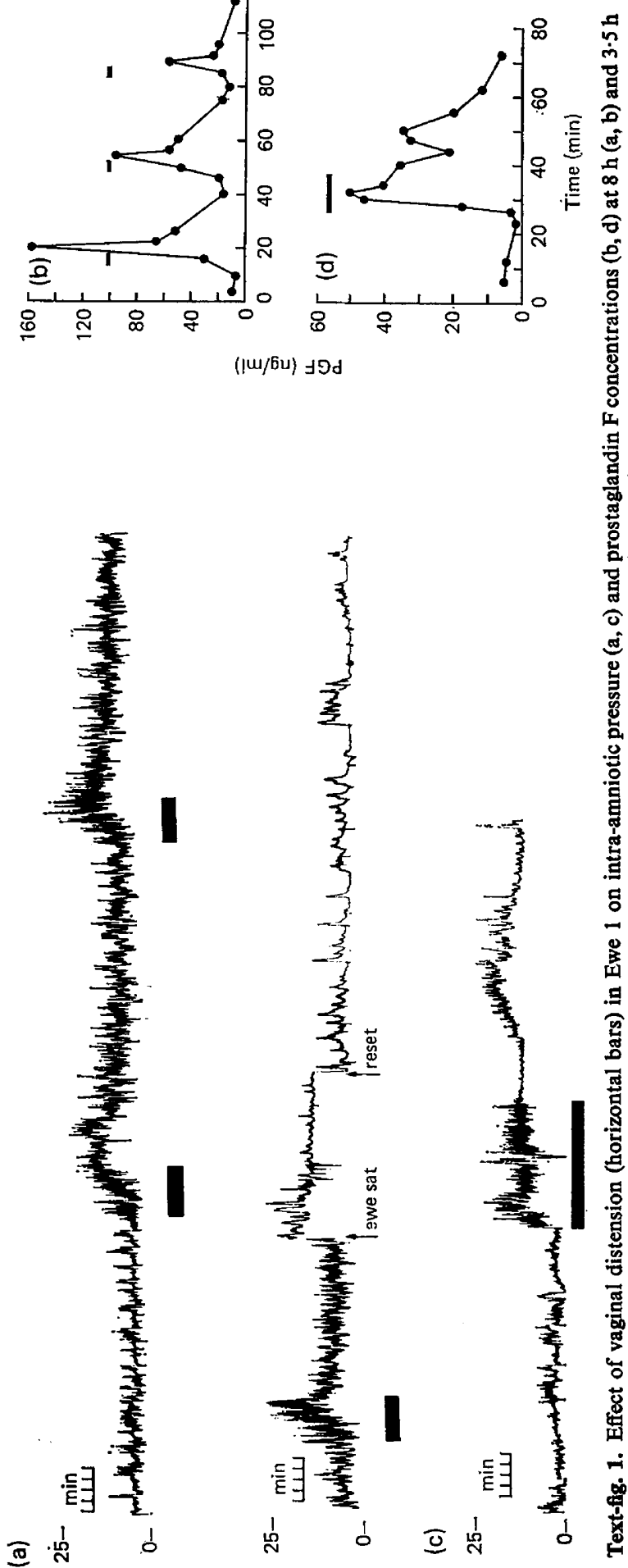

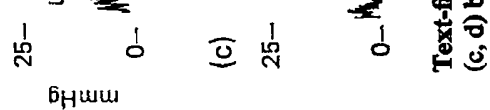




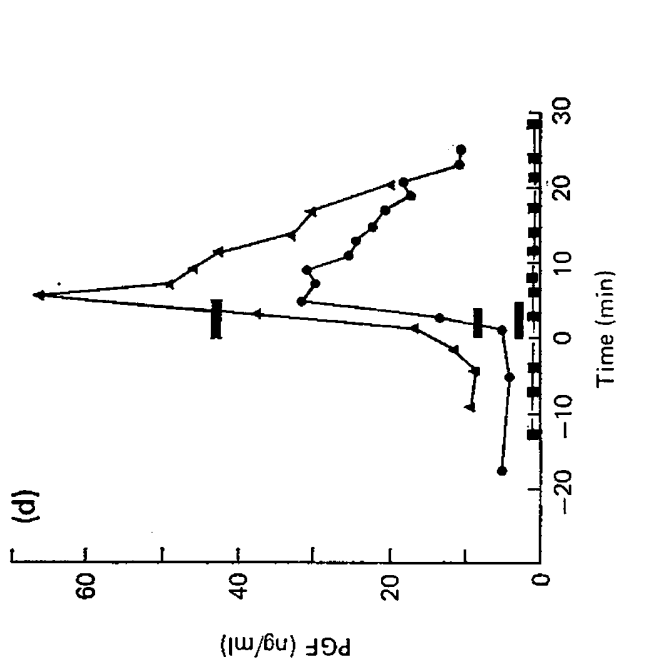

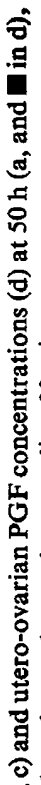

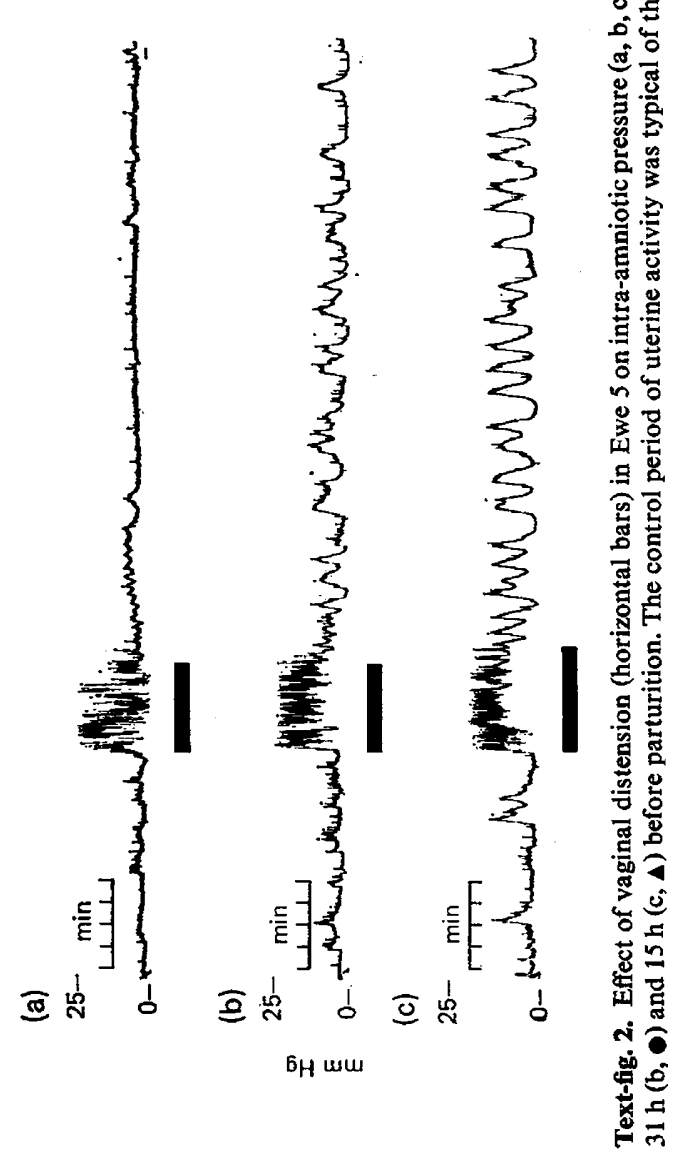


in response to vaginal distension closer to parturition, i.e. the abdominal straining and the time course of increasing PGF levels. Abdominal straining occurs immediately vaginal distension commences and probably represents a reflex unaffected by the endocrine environment. This effect will presumably be of importance in the expulsion of the fetus. The time course of elevation of PGF concentrations is consistent with previous work (Flint et al., 1975), but has now been shown not to be influenced by the hormonal changes associated with parturition. It has been shown that progesterone diminishes and oestrogen potentiates the release of oxytocin in response to vaginal distension (Roberts \& Share, 1969) while the uterus also becomes increasingly sensitive to oxytocin during late gestation (Hindson, Schofield \& Ward, 1969), perhaps due to rising basal levels of PGF, which lower the threshold for oxytocin stimulation (Liggins et al., 1973). The increasing uterine activity following vaginal distension close to parturition, as progesterone concentrations fall and oestrogen concentrations rise, could therefore be explained by an increased reflex release of oxytocin acting on an increasingly sensitive uterus.

The increasing elevation of PGF concentrations in response to vaginal distension close to parturition might also be explained in terms of increased oxytocin secretion. In addition, however, it seems likely that uterine PGF output in response to oxytocin is potentiated near term since the same trend in PGF output has been noted in response to exogenous oxytocin administration (Mitchell et al., 1975), when the quantity of oxytocin reaching the uterus is presumably not a limiting factor. The possibility that oxytocin affects uterine activity and PGF concentrations by separate mechanisms is supported by the finding that oxytocin can stimulate uterine activity in the presence of an inhibitor of PG synthesis which prevents a rise in plasma PGF concentrations (Roberts, Barcikowski, Wilson, Skarnes \& McCracken, 1975).

Oxytocin levels are increased in men and women following administration of PGs (Gillespie, Brummer \& Chard, 1972). If such an effect occurred in the sheep a spiral mechanism might be postulated whereby increasing quantitities of myometrial stimulants could account for the rapid nature of parturition in this species. Such a self-accentuating mechanism would be quiescent at early stages of gestation, but would gradually mature to optimal efficiency at term, awaiting only the final 'trigger' of cervical and vaginal distension by the descending fetal presenting parts.

We thank Dr B. J. Furr, I.C.I. Pharmaceuticals Division, Alderley Park, Cheshire, and Dr K. J. Thrower, Upjohn Ltd, Crawley, Sussex, for gifts of antisera, and Professor G. S. Dawes for the use of the animal facilities at the Nuffield Institute for Medical Research. M.D.M. acknowledges the support of an M.R.C. Studentship. This work was supported by M.R.C. Programme Grant No. G $971 / 809 / \mathrm{C}$.

\section{References}

Caldeyro-Barcia, R., Sica-Blanco, Y., Poseiro, J.J. Gonzalez-Panizza, V., Mendez-Bauer, C., Fielitz, C., Alvarez, H., Pose, S.V. \& Hendricks, C.H. (1957) A quantitative study of the action of synthetic oxytocin on the pregnant human uterus. $J$. Pharmac. exp. Ther. 121, 18-31.

Debackere, M., Peeters, G. \& Tuyttens, N. (1961) Reflex release of an oxytocic hormone by stimulation of genital organs in male and female sheep studied by a cross-circulation technique. $J$. Endocr. 22, 321-334.

FERguson, J.K.W. (1941) A study of the motility of the intact uterus at term. Surgery Gynec. Obstet. 73, 359-366.

Flint, A.P.F., Anderson, A.B.M., Patten, P.T. \& TurnBull, A.C. (1974) Control of utero-ovarian venous prostaglandin $F$ during labour in the sheep: acute effects of vaginal and cervical stimulation. J. Endocr. 63, 67-87.
Flint, A.P.F., Forsling, M.L., Mitchell, M.D. \& Turnbull, A.C. (1975) Temporal relationship between changes in oxytocin and prostaglandin $F$ levels in response to vaginal distension in the pregnant and puerperal ewe. J. Reprod. Fert. 43, 551-554.

Gillespie, A., Brummer, H.C. \& Chard, T. (1972) Oxytocin release by infused prostaglandin. Br. med. J. 1, 543-544.

Hindson, J.C., Schofield, B.M. \& WARd, W.R. (1969) The effect of progesterone on recorded parturition and on oxytocin sensitivity in the sheep. J. Endocr. 43, 207-215.

Liggins, G.C. (1968) Premature parturition after infusion of corticotrophin or cortisol into foetal lambs. J. Endocr. 42, 323-329.

Liggins, G.C., Fairclough, R.J., Grieves, S.A., KendALl, J.Z. \& KNOX, B.S. (1973) The mechanism of initiation of parturition in the ewe. Recent Prog. Horm. Res. 29, 111-159. 
Mati, J.K.G., Horrobin, D.F. \& Bramley, P.S. (1973) Induction of labour in sheep and in humans by single doses of corticosteroids. Br. med. J. 2, 149-151.

Mitchell, M.D., Flint, A.P.F, \& Turnbull, A.C. (1975) Stimulation by oxytocin of prostaglandin $F$ levels in uterine venous effluent in pregnant and puerperal sheep. Prostaglandins 9, 47-56.

Peeters, G., De Vos, N. \& Houvenaghel, A. (1971) Elimination of the Ferguson Reflex by section of the pelvic nerves in the lactating goat. J. Endocr. 49, 125-130.

ROBERTS, J.S. \& SHARE, L. (1968) Oxytocin in plasma of pregnant, lactating and cycling ewes during vaginal stimulation. Endocrinology 83, 272-278.

RoberTs, J.S. \& SHARE, L. (1969) Effects of progesterone and oestrogen on blood levels of oxytocin during vaginal distension. Endocrinology 84, 1076-1081.

Roberts, J.S., Barcikowski, B., Wilson, L., Skarnes, R.C. \& MCCracken, J.A. (1975) Hormonal and related factors affecting the release of prostaglandin $F_{2 \alpha}$ from the uterus. J. Steroid Biochem. 6, 1091-1097.

Sharma, S.C. \& Fitzpatrick, R.J. (1974) Effect of oestradiol-17 $\beta$ and oxytocin treatment on prostaglandin $F \alpha$ release in the anoestrous ewe. Prostaglandins 6, 97-105.

Thorburn, G.D., Nicol, D.H., Bassett, J.M., Shutt, D.A. \& Cox, R.I. (1972) Parturition in the goat and sheep: changes in corticosteroids, progesterone, oestrogens and prostaglandin F. J. Reprod. Fert., Suppl. 16, 61-84.

Received 17 May 1976 